\title{
Effect of sodium hydroxide on the tensile properties of sugar palm fibre reinforced thermoplastic polyurethane composites
}

\author{
A.A. Mohammed ${ }^{1,2}$, D. Bachtiar,", J.P. Siregar ${ }^{1}$ and M.R.M. Rejab ${ }^{1}$ \\ ${ }^{1}$ Faculty of Mechanical Engineering, \\ Universiti Malaysia Pahang, Pekan 26600 Pahang Darul Makmur, Malaysia \\ *Corresponding author, Email: dandi@ump.edu.my \\ Tel. +6094246357; Fax: +6094246222 \\ ${ }^{2}$ Department of Materials Engineering, University of Technology, Baghdad, Iraq
}

\begin{abstract}
Global warming, environmental changes, and other problems have been increasing in the last decade. Researchers and scholars want to safeguard life on the earth by making ecofriendly products, like natural composite materials. Natural fibre is environmentally valuable because of its biodegradable nature. However, there is a serious problem caused by the incompatibility between fibre and matrix. In this work, sugar palm fibre was combined with thermoplastic polyurethane composites after treatment with different concentrations of sodium hydroxide from 2 to $6 \%$ to enhance the compatibility between them. An extrusion machine was used to combine $30 \%$ by weight of the sugar palm fibre and $70 \%$ by weight of thermoplastic polyurethane composites. The temperature, rotation velocity, and fibre size were fixed at (180-190-200 $\left.{ }^{\circ} \mathrm{C}\right), 40 \mathrm{rpm}$ and $250 \mu \mathrm{m}$ respectively. The composite was characterized according to ASTM D638. The sodium hydroxide treatment of the fibre could provide a good tensile modulus of $440 \mathrm{MPa}$ at $2 \%$ of $\mathrm{NaOH}$, and strain of $41.6 \%$ at $6 \% \mathrm{NaOH}$ of the composite. However, the tensile strength was decreased, where the highest amount of $5.49 \mathrm{MPa}$ recorded at $6 \% \mathrm{NaOH}$. Meanwhile, the tensile modulus and strain of the composites are found to be much better than those of untreated ones. In contrast, the tensile strength was still not improved.
\end{abstract}

Keywords: Mechanical properties; sugar palm fibre; thermoplastic polyurethane; composites; alkali treatment.

\section{INTRODUCTION}

Nowadays, it is important to reduce environmental impacts such as global warming. Global warming is generated by the consumption of petroleum, a non-renewable resource. Therefore, increasingly, numerous ecologically aware studies have pointed to the use of alternative environmentally friendly materials. Natural fibre has unique characteristics and many outstanding advantages over synthetic fibre, which make it an attractive alternative to traditional materials [1,2]. Natural fibres such as hemp, flax, abaca, sisal, jute, henequen, kenaf, ramie, sugar palm, oil palm, pineapple leaf, banana pseudo-stem, sugarcane bagasse, coir, rice husk, wood, bamboo, chicken feathers, wool, silk and cotton have been reported as being used as fibre in polymer composites [3-9]. Natural fibrereinforced plastics are gaining more attention from researchers and industry due to their cost-effectiveness, lighter weight, lower abrasion of equipment and renewability, among the several benefits of natural fibre composites [10-12]. For these reasons, in construction and the furniture, automotive and packaging industries, materials like sugar palm fibre 
are now used [7, 13-16]. Sugar palm fibre (SPF) is a potential source of natural fibre from Arenga pinnata, a member of the Palmae family. It is known for its high durability and resistance to seawater. These two characteristics are the main advantages of sugar palm fibre [17]. In addition, the consideration of using SPF as reinforcement in composites is based not only on its excellent properties, but also on its contribution to the conservation of forestry, biodiversity, utilisation of plant waste, and on the abundant availability of the fibres at a very low cost [18]. Moreover, it is known as a fast-growing palm that is able to reach maturity within 10 years [19]. This plant commonly grows in tropical regions such as the Philippines, Malaysia and Indonesia. It is naturally a forest species. The full length of the trunk of an Arenga pinnata tree is completely covered by black fibre. This black fibre can be used for brooms, paint brushes, septic tank filters, clear water filters, door mats, carpets, ropes, chair/sofa cushions, and for fish nests to hatch eggs. In certain regions, the traditional application of ijuk includes handcraft for kupiah (Acehnese typical headgear used in prayer) and roofing for traditional houses in Mandailing, North Sumatra [20]. Yet sugar palm fibre remains largely unknown by many people and very little information is available about it, so more research needs to be conducted to reveal its significance and to promote its usefulness for the benefits of the public [18]. However, SPF, like all natural fibre, faces some difficulties that prevent its widespread use. The poor adhesion between hydrophobic polymers and hydrophilic fibre implies poor properties for the composites. The hydrophilic nature arises from the fact that cellulose is the main component of all natural fibres, and the elementary unit of a cellulose macromolecule is anhydro-d-glucose, which contains three hydroxyl $(\mathrm{OH})$ groups. These hydroxyl groups have been reported to form hydrogen bonds inside the macromolecule itself, and between other cellulose macromolecules. The hydrogen bonds give the natural fibre its hydrophilic nature $[4,2,13]$.

This problem may be rectified by chemically treating the fibre surfaces before fabricating the composites [21-23]. Alkali $(\mathrm{NaOH})$ treatment is an important chemical treatment method used to enhance interfacial adhesion between natural fibre and polymer, as well as the mechanical, physical and thermal properties of the fibre. Alkali treatment is also a good alternative as these chemicals in many cases swell the cell wall of the matrix structure and give better penetration. A group of researchers analysed the effect of fibre treatment on the mechanical properties of unidirectional sisal-reinforced epoxy composites. They also reported that (i) the fibre strength and (ii) the adhesion between the fibre bundles and the matrix are improved by alkali treatment of sisal fibre [24]. Alkali treatment removes the hemicellulose, splits the fibre into fibrils, and leads to a closer packing of the cellulose chain due to the release of internal strain, which in turn enhances the mechanical properties of the fibre [25]. $\mathrm{NaOH}$ is the most common chemical treatment used to clean the fibre surface and enhance fibre properties. The following Scheme 1 explains the mechanism of the reaction between the natural fibre and the $\mathrm{NaOH}$ solution [26]. It is clear that the $\mathrm{OH}$ groups are separated from the fibre by the action of the $\mathrm{Na}^{+2}$ ions to produce a new component which is (fibre- $\mathrm{NaO}$ ) instead of (fibre- $\mathrm{OH}$ ) [13, 2628].

$$
\text { Natural fibre }-\mathrm{OH}+\mathrm{NaOH} \longrightarrow \text { Natural fibre }-\mathrm{NaO}+\mathrm{H}_{2} \mathrm{O}
$$

Scheme 1. The reaction between the SPF and the $\mathrm{NaOH}$ solution.

Untreated fibre is covered with hemicellulose, lignin, pectin, waxy substances, and natural oils. Treatment with $\mathrm{NaOH}$ reveals the fibrils and gives the fibre a rough 
surface topography [29]. Previous work used different sisal fibre loadings of $0.5,1,2$, and $4 \%$ by weight of reinforced polyester. This fibre was treated with different concentrations of $\mathrm{NaOH}$ ranging between 4 and $10 \%$ at room temperature, and the results reported that $4 \%$ of $\mathrm{NaOH}$ gained the maximum tensile strength properties [30]. During alkali treatment, the fibre's physical structure changes as a result of the alkali bleaching action, which removes waxy materials and impurities. This action often leads to improvement in the interfacial bonding between the fibre and matrix by giving the fibre a rougher surface. Despite the benefits brought by environmentally friendly composites, it is anticipated that in the future, reduction in petroleum reserves will provoke a decrease in the use of petroleum-based resins, and the use of plant-based biodegradable resins such as polylactic acid (PLA) will probably increase. Therefore, there has recently been an increase in studies on fully gree natural fibre composites [31-35]. Thermoplastic polyurethane (TPU) has been chosen due to its good mechanical properties and rubber-like elasticity. Moreover, it is polar, which reduces the fibre-polymer incompatibility [36]. Thus, the present work studied the effect of different $\mathrm{NaOH}$ concentrations from 2, 4 and $6 \%$ on the fibre-matrix adhesion of TPU and SPF and tensile properties. The tensile properties of the SPF/TPU composites were measured according to ASTM Standard D638 [37]. To the best of the researchers' knowledge, SPF/TPU composites have not yet been investigated by other researchers.

\section{MATERIALS AND METHODS}

The materials used in this study are Estane ${ }^{\circledR} 58311$, an 85A polyether-type thermoplastic polyurethane (TPU) (Figure 1(a)), and short sugar palm fibre (SPF) (Figure 1(b)); the specific gravity of the TPU is $1.21 \mathrm{~g} / \mathrm{cm}^{2}$. The melting temperature is $210^{\circ} \mathrm{C}$. Sodium hydroxide pellets $(\mathrm{NaOH})$ used are Grade AR (Figure 1(c)).

\section{Preparation of Fibre}

The fibre was washed in water to remove dust and impurities, then dried for two weeks at atmosphere pressure and room temperature. Afterwards, they were crushed in a grinding machine Retsch ZM 200, and subsequently shortened by sieving to a size of 250 $\mu \mathrm{m}$ using an auto shaker type FRITSCH in order to make them suitable for the final application [38].

\section{Treatment of Fibre}

The hydrophilic nature of the SPF makes the adhesion between it and the hydrophobic TPU poor. This causes weakness in the structure of composites [39]. So, the clean, dried, and ground fibre was washed eight times using distilled water. Different weights of $\mathrm{NaOH}$ were dissolved in a flask with distilled water for three different time periods, then left to stand for around 30 minutes to let the solution become homogeneous and cool. Then, after soaking in sodium hydroxide solution for 90 minutes, finally the fibre was washed in distilled water eight times [13, 27, 28]. Thereafter, the fibre was left to dry for around two weeks at atmosphere pressure and room temperature [13]. Figure 2 shows the equipment used for this process: the flask and cylinder having $900 \mathrm{ml}$ and $100 \mathrm{ml}$ volume respectively to contain the fibre and the solution. The cylinder was used to control the volume of $\mathrm{NaOH}$ in the distilled water which was needed for the reaction. Table 1 listed the correlation of weight values of $\mathrm{NaOH}$ with concentrations. 

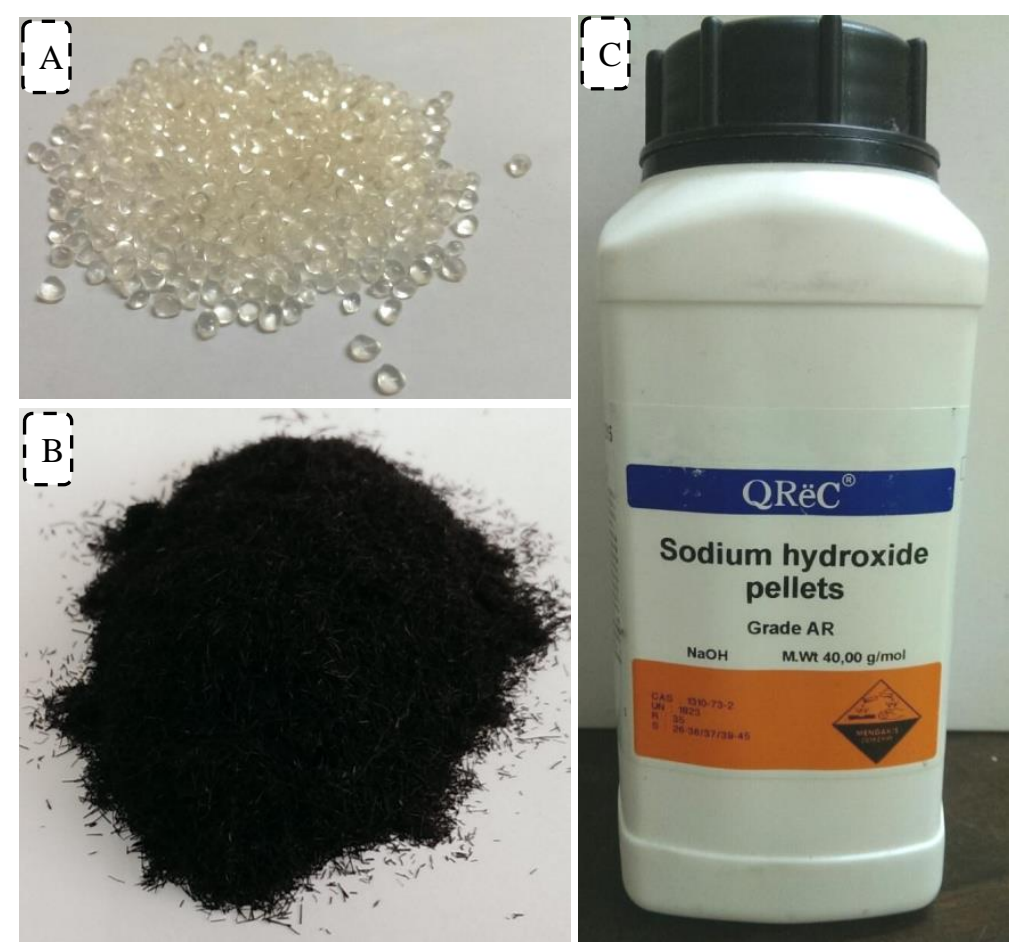

Figure 1. (a) Pure TPU, (b) SPF, and (c) sodium hydroxide.

To change the $\mathrm{NaOH}$ concentration to the weight it must be calculated from the following equation:

$$
\begin{aligned}
M & =\frac{W}{M \cdot w t} * \frac{1000}{V} \\
W & =\frac{M * M \cdot w t * V}{1000}
\end{aligned}
$$

where: $\mathrm{M}=$ concentration $(\mathrm{mol} / \mathrm{L})$

$\mathrm{V}=$ volume $(\mathrm{ml}), \mathrm{V}=1000 \mathrm{ml}$

$\mathrm{W}=$ weight $(g)$

$\mathrm{M} \cdot \mathrm{wt}=$ molecular weight $(\mathrm{g} / \mathrm{mol}), \mathrm{M} \cdot \mathrm{wt}$ for $\mathrm{NaOH}=40 \mathrm{~g} / \mathrm{mol}$

Table 1. Correlation of weight values of $\mathrm{NaOH}$ with concentrations.

\begin{tabular}{ccc}
\hline Number & $\mathrm{NaOH}(\%)$ & $\mathrm{NaOH}(\mathrm{g})$ \\
\hline 1 & 2 & 80 \\
2 & 4 & 160 \\
3 & 6 & 240 \\
\hline
\end{tabular}

\section{Composite Preparation}

SPF/TPU composite specimens were compounded using a Thermo SCIENTIFIC EUROLAB 16 extruder machine. The optimum rotating speed and temperature were set as $40 \mathrm{rpm}$, and $180-190-200^{\circ} \mathrm{C}$ [38]. The author in a previous work studied the effects of different fibre loadings on the mechanical properties of the SPF/TPU composites. The 
result proved that the best mechanical properties are for $10 \%$ fibre in $90 \%$ TPU [39]. However, the $10 \%$ fibre loading is too small to be very feasible, so a $30 \%$ fibre loading was fixed throughout the study, with $250 \mu \mathrm{m}$ fibre size [38] and a soaking time of 1.5 hour to enhance it. The fibre was treated with different concentrations of $\mathrm{NaOH}$ of 2, 4, and $6 \%$. A $30 \%$ fibre weight mixed into $70 \%$ TPU was extruded in the extruder machine under optimum temperature conditions of $180-190-200^{\circ} \mathrm{C}$ and at $40 \mathrm{rpm}$ [38]. Then the extruded composite pellets were pressed by using a square mould and then using a 25 ton hot press LOTUS SCIENTIFIC for compression moulding by setting the press pressure at $10 \mathrm{MPa}$ and $190^{\circ} \mathrm{C}$ for $10 \mathrm{~min}$ [40]. Prior to the full pressure, the sample was pre-heated until reaching $190^{\circ} \mathrm{C}$. Then the prepared sheet was cooled to $50^{\circ} \mathrm{C}$. A stainless steel mould with dimensions of $200 \times 200 \times 3 \mathrm{~mm}$, length, width, and thickness respectively, was used.

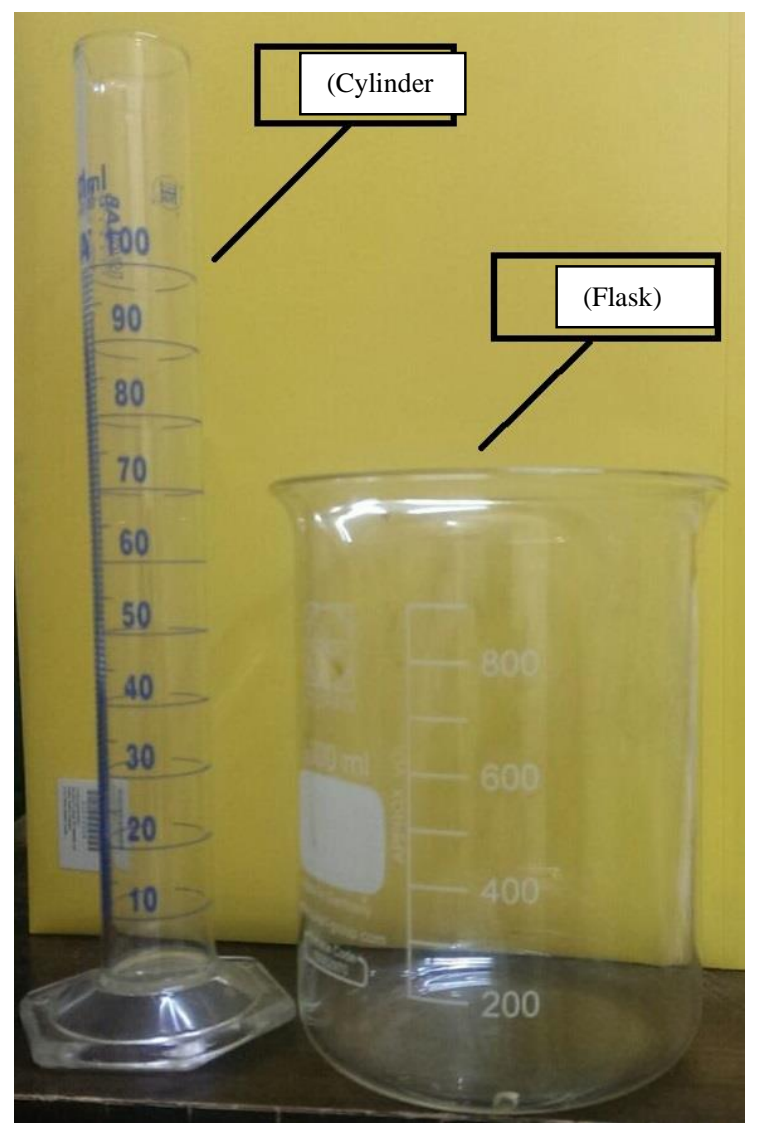

Figure 2. Equipment used for treatment: cylinder and flask.

\section{Mechanical Characterization}

\section{Tensile Testing}

Tensile strength is a measurement of the ability of a material to withstand forces that tend to pull it apart. It determines to what extent the material stretches before breaking. Tensile properties were measured using an Instron tensile model NVLAP 5569, 3369Q3720 machine (Figure 3(a)). This consists of a computer to control the device using special software, and a printer to provide the data as hard copy. The specifications of the Instron tester explain that the maximum displacement is $200 \mathrm{~mm}$, and the highest load is $50 \mathrm{kN}$. 
Effect of sodium hydroxide on the tensile properties of sugar palm fibre reinforced thermoplastic polyurethane composites

The five specimens were prepared by cutting them from the sample sheets into dumbbell shapes using a manual saw.
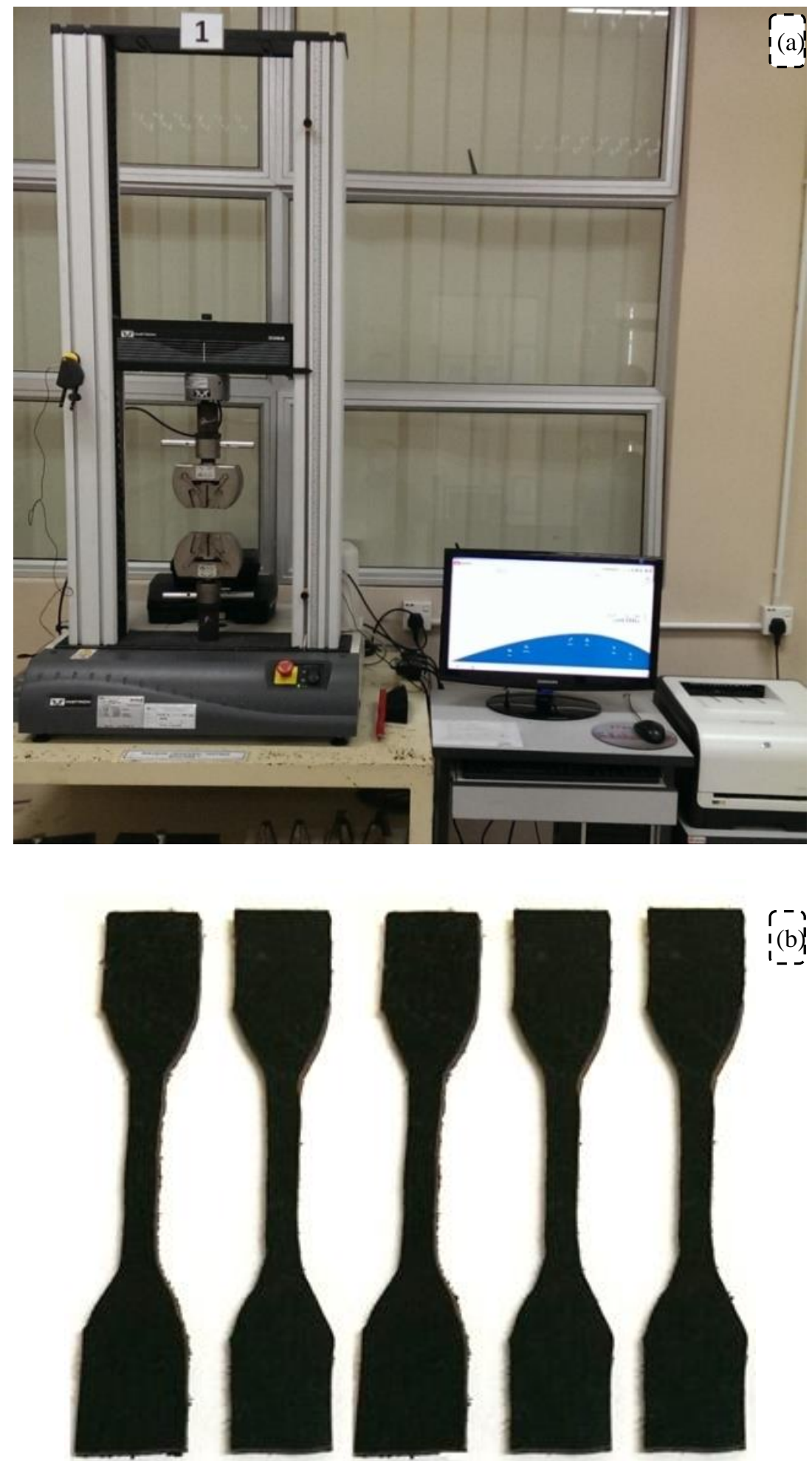

Figure 3. (a) Instron tensile model NVLAP 5569, 3369Q3720 machine, (b) tensile specimens for every sample. 
Five specimens were tested with a crosshead speed of $5 \mathrm{~mm} /$ minutes, according to ASTM D638 [37]. The tensile specimens are shown in Figure 3(b). The ability to obtain accurate results depends not only on the quality of the testing system, but also on the errors that can be introduced into it. Therefore, Table 2 represents the tensile strength, modulus, strain, and the statistical analysis, such as the average, standard deviation and error for the untreated and treated SPF/TPU composites, in order to know the range of accuracy.

Table 2. Tensile strength, modulus, strain, average, standard deviation and error for the untreated and treated SPF/TPU composites with different $\mathrm{NaOH}$ concentrations.

\begin{tabular}{|c|c|c|c|c|c|c|c|c|}
\hline No & $\begin{array}{c}\mathrm{NaOH} \\
(\%)\end{array}$ & Strength & Modulus & Strain & $\begin{array}{c}\mathrm{NaOH} \\
(\%)\end{array}$ & Strength & Modulus & Strain \\
\hline & $0 \%$ & & & & $2 \%$ & & & \\
\hline 1 & $\begin{array}{c}\mathrm{NaOH} \\
0 \%\end{array}$ & 10.38 & 105.53 & 21.21 & $\begin{array}{c}\mathrm{NaOH} \\
2 \%\end{array}$ & 4.44 & 400 & 22 \\
\hline 2 & $\begin{array}{c}\mathrm{NaOH} \\
0 \%\end{array}$ & 9.13 & 96.32 & 18.94 & $\begin{array}{c}\mathrm{NaOH} \\
2 \%\end{array}$ & 4.23 & 400 & 18 \\
\hline 3 & $\begin{array}{c}\mathrm{NaOH} \\
0 \%\end{array}$ & 8.9 & 90.27 & 22.98 & $\begin{array}{c}\mathrm{NaOH} \\
2 \%\end{array}$ & 4.07 & 500 & 11 \\
\hline 4 & $\begin{array}{c}\mathrm{NaOH} \\
0 \%\end{array}$ & 11.71 & 95.84 & 30.05 & $\begin{array}{c}\mathrm{NaOH} \\
2 \%\end{array}$ & 4.56 & 500 & 18 \\
\hline \multirow[t]{4}{*}{5} & $\mathrm{NaOH}$ & 9.36 & 88.48 & 23.99 & $\mathrm{NaOH}$ & 4.64 & 400 & 21 \\
\hline & Average & 9.896 & 95.288 & 23.434 & Average & 4.388 & 440 & 18 \\
\hline & Std. Dev. & 1.16092 & 6.66704 & 4.1662 & Std. Dev. & 0.23552 & 54.7723 & 4.30116 \\
\hline & Std. Err. & 0.51918 & 2.98159 & 1.86318 & Std. Err. & 0.10533 & 24.4949 & 1.92354 \\
\hline \multirow[t]{2}{*}{ No } & $\mathrm{NaOH}(\%)$ & Strength & Modulus & Strain & $\mathrm{NaOH}(\%)$ & Strength & Modulus & Strain \\
\hline & $4 \%$ & & & & $6 \%$ & & & \\
\hline 1 & $\begin{array}{c}\mathrm{NaOH} \\
4 \%\end{array}$ & 3.4 & 500 & 13 & $\begin{array}{c}\mathrm{NaOH} \\
6 \%\end{array}$ & 5.4 & 300 & 37 \\
\hline 2 & $\begin{array}{c}\mathrm{NaOH} \\
4 \%\end{array}$ & 3.8 & 400 & 17 & $\begin{array}{c}\mathrm{NaOH} \\
6 \%\end{array}$ & 5.32 & 300 & 50 \\
\hline 3 & $\begin{array}{c}\mathrm{NaOH} \\
4 \%\end{array}$ & 3.52 & 400 & 12 & $\begin{array}{c}\mathrm{NaOH} \\
6 \%\end{array}$ & 5.02 & 300 & 28 \\
\hline 4 & $\begin{array}{c}\mathrm{NaOH} \\
4 \%\end{array}$ & 3.79 & 400 & 14 & $\begin{array}{c}\mathrm{NaOH} \\
6 \%\end{array}$ & 5.71 & 300 & 47 \\
\hline \multirow[t]{4}{*}{5} & $\mathrm{NaOH}$ & 3.04 & 500 & 9 & $\mathrm{NaOH}$ & 6 & 300 & 46 \\
\hline & Average & 3.51 & 440 & 13 & Average & 5.49 & 300 & 41.6 \\
\hline & Std. Dev. & 0.31448 & 54.7723 & 2.91548 & Std. Dev. & 0.3763 & 0 & 9.01665 \\
\hline & Std. Err. & 0.14064 & 24.4949 & 1.30384 & Std. Err. & 0.16829 & 0 & 4.03237 \\
\hline
\end{tabular}

Std. Dev: Standard deviation.

Std. Err.: Standard error.

The units of strength, modulus are (MPa), while the strain is (\%).

\section{RESULTS AND DISCUSSION}

\section{Tensile Strength}

Figure 4 shows the tensile strength with different sodium hydroxide concentrations. Clearly, the tensile strength increases gradually with increasing $\mathrm{NaOH}$ concentration. The 
strength was $4.39 \mathrm{MPa}$ at $2 \%$ of $\mathrm{NaOH}$ then increased to $5.49 \mathrm{MPa}$ at $6 \% \mathrm{NaOH}$ concentration by weight. This change in the chemical treatment concentration on the SPF caused an alteration in the tensile strength values. The tensile strength of sugar palm fibre reinforced with polyurethane rose from 4.39 to $5.49 \mathrm{MPa}$. Meanwhile, there was heavy interlocking between the fibre and matrix, which increased the strengthening in the composite structure and meant that this specimen had the highest tensile strength and strain. This is in agreement with the findings of many researchers who used different sisal fibre loadings of $0.5,1,2$, and $4 \%$ by weight, reinforced with polyester, and then treated it with different concentrations of $\mathrm{NaOH}$ between $4 \%$ and $10 \%$ at room temperature. Moreover, this is also in agreement with the results of researchers who found the maximum tensile strength properties at $4 \%$ wt of $\mathrm{NaOH}[41,42]$. In addition, previous work by El-Shekeil et al. [17] proved the same decreasing in the tensile properties after using 2, 4, and $6 \%$ of $\mathrm{NaOH}$ to treat kenaf fibre reinforced thermoplastic polyurethane composites. This work showed the reason for this decrease, indicating the $\mathrm{NaOH}$ deposits on the fibre surface. Moreover, the author referred to washing the fibre six times after the treatment process [28]. However, in this work the washing was for eight times to give a better chance of removing the entire $\mathrm{NaOH}$ residue. However, the values for all the fibres treated by $\mathrm{NaOH}$ solution were still lower than the untreated value. The standard deviation for untreated fibre was the highest value compared with the treated value, which was recorded as gradually decreasing, as illustrated in Table 2. Meanwhile, the standard error for untreated fibre recorded the maximum value compare with all the treated values for 2,4 , and $6 \%$ of $\mathrm{NaOH}$, as illustrated in Table 2 . This may indicate that the percentages of alkali treatment must be increased to get improved levels, which is in agreement with Xue et al., who reviewed the chemical treatment of natural fibre in different systems [26, 42]. Perhaps the alkali treatment needs to be enhanced by another method such as using $\mathrm{KMnO}_{4}$ [43].

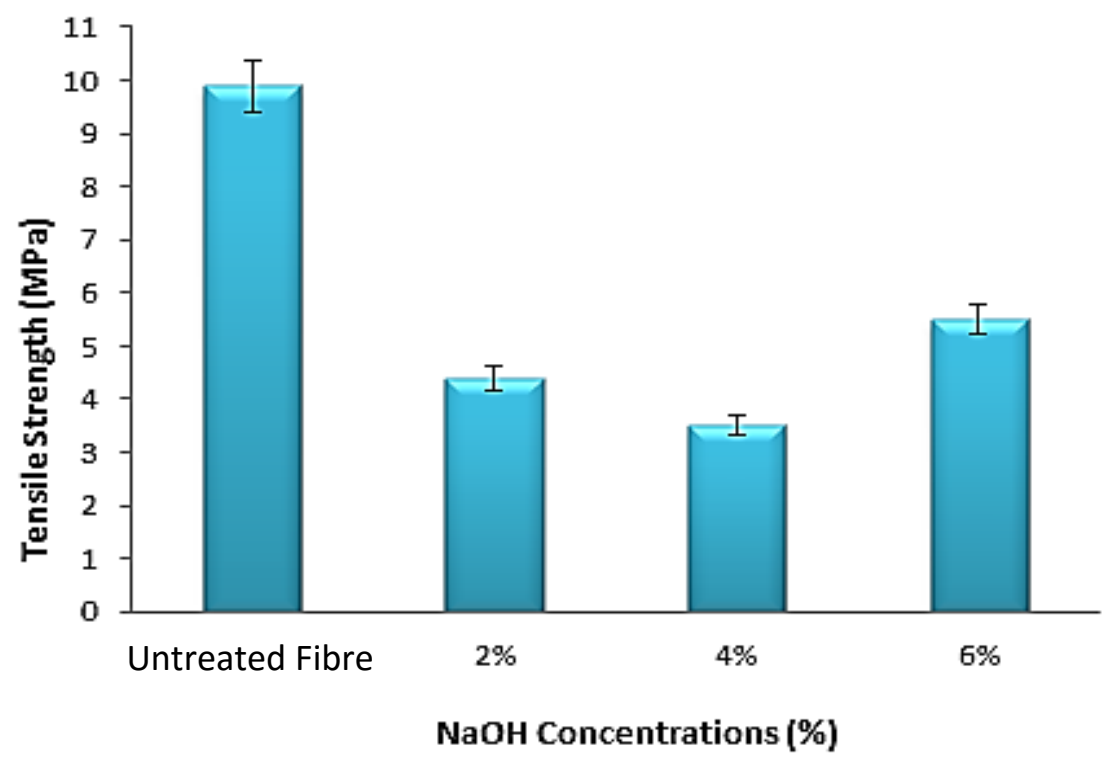

Figure 4. Tensile strength with sodium hydroxide concentration.

\section{Tensile Modulus}

Figure 5 shows the tensile modulus with different sodium hydroxide concentrations. It is clear that the modulus decreased gradually with increasing $\mathrm{NaOH}$ concentration. The 
modulus was $440 \mathrm{MPa}$ at $2 \%$ of $\mathrm{NaOH}$ then rose to $320 \mathrm{MPa}$ at $6 \% \mathrm{NaOH}$. There was a dramatic rise in the modulus for all $\mathrm{NaOH}$ concentrations compared with fibre composite untreated with $\mathrm{NaOH}$. These results are in agreement with those of many authors who used $\mathrm{NaOH}$, which can remove lignin and wax to make the surface rougher [44]. The standard deviation for treated fibre at $6 \%$ was the lowest value compared with all the treated and untreated values, as illustrated in Table 2. Meanwhile, the standard error for fibre treated with $6 \%$ recorded the lowest value compared with the untreated and other treated values, as illustrated in Table 2 . The main component of natural fibre is cellulose. The elementary unit of a cellulose macromolecule is a hydro-d-glucose. A hydro-dglucose contains three hydroxyl $(\mathrm{OH})$ groups, which have been reported to form hydrogen bonds. Finally, these hydrogen bonds give the natural fibre a hydrophilic nature. This has improved these mechanical properties to yield the best results, as shown before in Scheme $1[22]$.

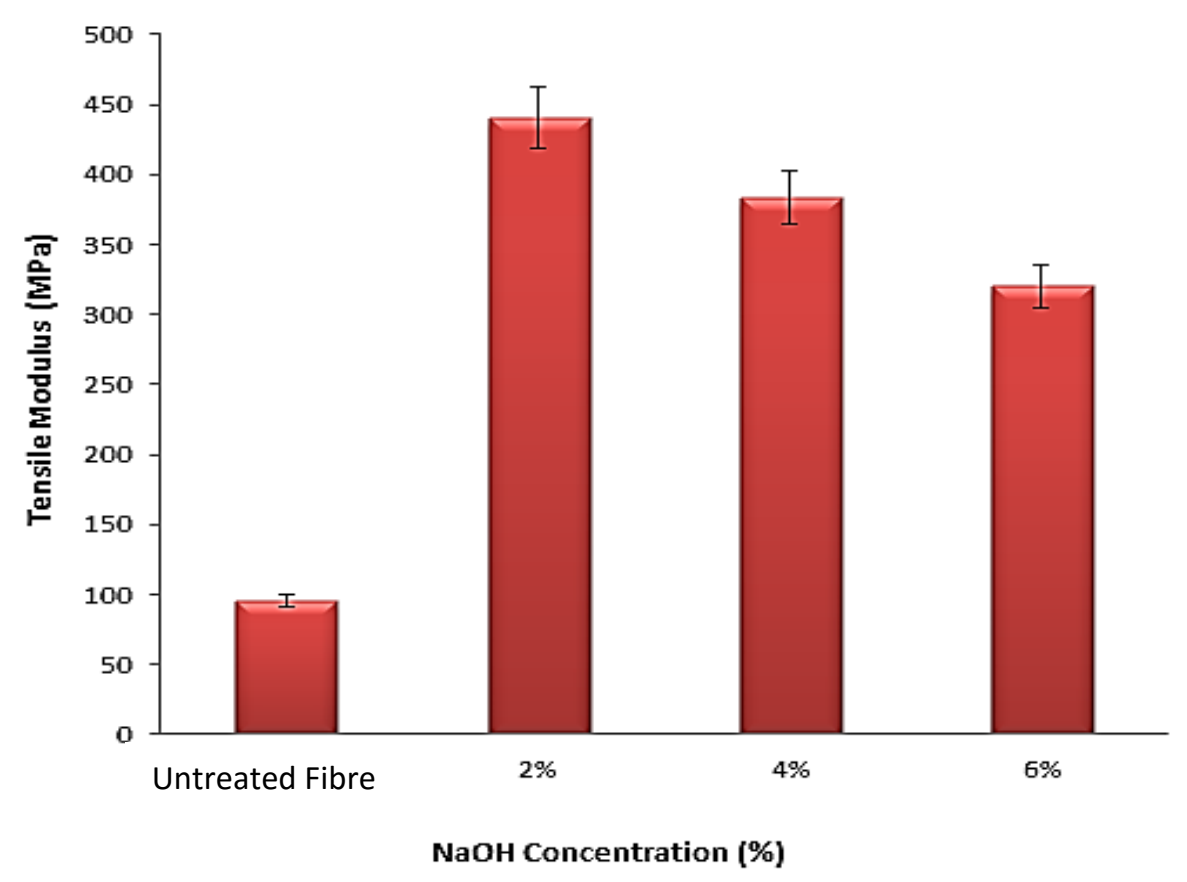

Figure 5. Tensile modulus with sodium hydroxide concentrations.

\section{Tensile Strain}

Figure 6 shows the tensile strain with different sodium hydroxide concentrations. It is clear that the strain increases with increasing $\mathrm{NaOH}$ concentration. The strain was $18 \%$ at $2 \% \mathrm{NaOH}$, and then it increased to $41.6 \%$ at $6 \% \mathrm{NaOH}$. There was a dramatic rise of strain for the $6 \% \mathrm{NaOH}$ concentration compared with the other composites, for the same reason as mentioned above in increasing the tensile strength. In addition, $\mathrm{NaOH}$ is used to remove lignin and wax to make the surface rougher [44]. The standard deviations for untreated fibre and fibre treated with 2 , and $4 \%$ were the lowest compared with the value for $6 \%$ treated $\mathrm{NaOH}$ which rose significantly, as illustrated in Table 2. Meanwhile, the standard error for fibre treated with $6 \%$ recorded the highest value compared with the untreated and treated values as illustrated in Table 2. The natural fibre consists of cellulose, and the elementary unit of its macromolecule is a hydro-d-glucose. The hydrod-glucose includes three hydroxyl collections, which have been observed to form 
hydrogen bonds as shown in Scheme 1. Finally, these hydrogen bonds give the natural fibre a hydrophilic nature that has been improved by the treatment to yield the best tensile strain results $[22,26]$.

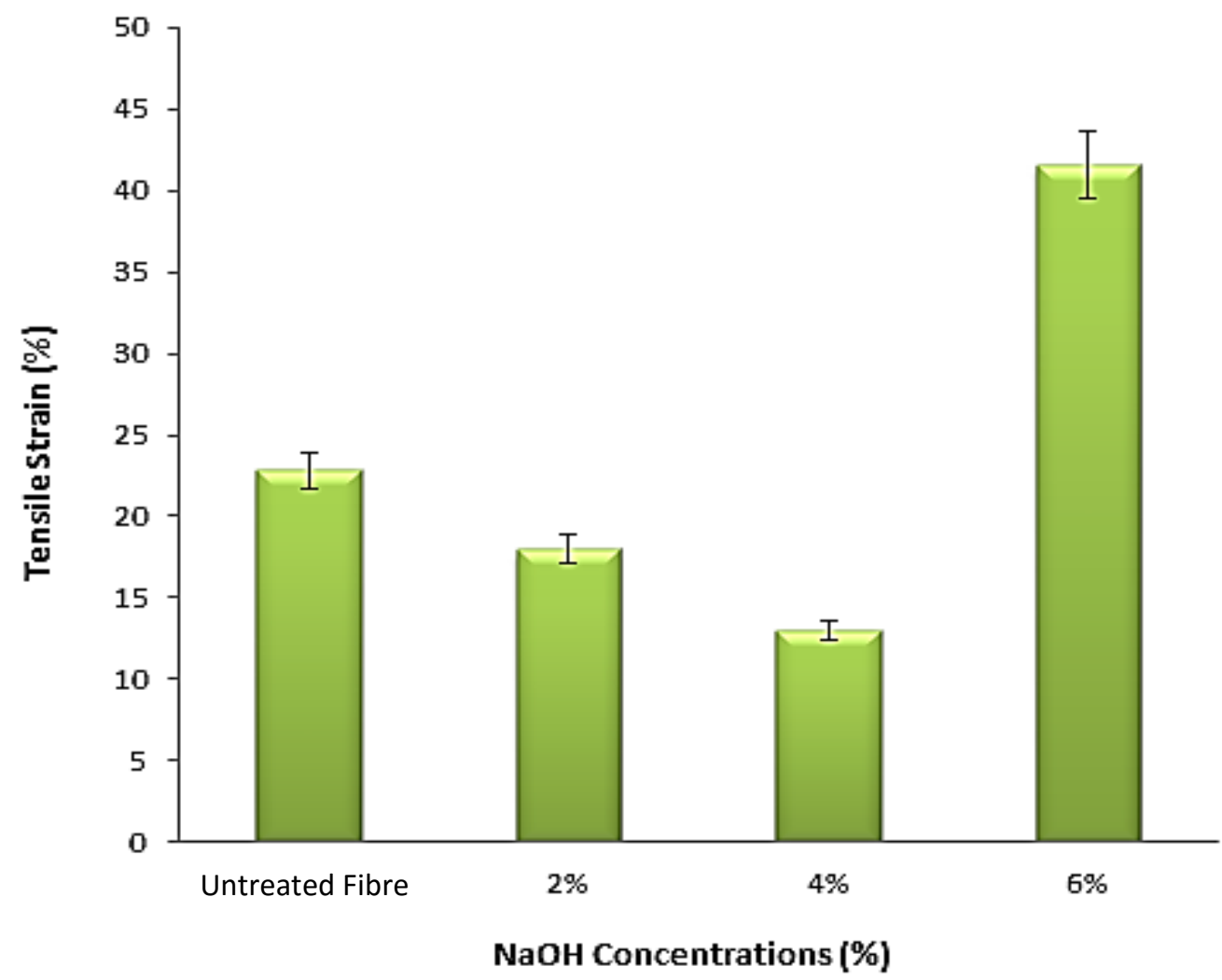

Figure 6. Tensile strain with sodium hydroxide concentrations.

\section{CONCLUSIONS}

A study has been conducted on the effects of sodium hydroxide solution treatment on the mechanical properties of sugar palm fibre reinforced thermoplastic polyurethane composites. From the above results, it can be concluded that:

- The chemical treatment by sodium hydroxide solutions improves the tensile properties of the final composite systems especially in terms of tensile modulus and strain. The highest concentration of chemical solution $(\mathrm{NaOH})$ recorded the best tensile strain in the composite, giving $41.6 \%$ compared to the untreated fibre at $22 \%$. Moreover, the tensile modulus showed the maximum amount at $2 \%$ of $\mathrm{NaOH}$ with $440 \mathrm{MPa}$. In contrast, the values of tensile strength for all types of $\mathrm{NaOH}$ treatment are still lower than the untreated fibre at 9.89 MPa. Meanwhile, the highest values for treated fibre recorded at $6 \%$ of $\mathrm{NaOH}$ were $5.49 \mathrm{MPa}$.

- The sodium hydroxide treatment of sugar palm fibre improves the structure of the prepared composite material by removing waxy materials and impurities. This action often leads to improvement in the interfacial bonding, and in the compatibility reaction between the natural sugar palm fibre and thermoplastic polyurethane, thus improving their surface by making it rougher and having better final tensile properties. 
- The treatment of the SPF with sodium hydroxide needs to be upgraded because the SPF/TPU composites do not achieve a higher tensile strength value than the untreated SPF in composites. So, the use of a different method or an upgrade of this treatment is very important to get the best tensile test. Perhaps the alkali treatment needs to be enhanced by another method such as a $\mathrm{KMnO}_{4}$ treatment.

\section{ACKNOWLEDGEMENTS}

The authors wish to thank Universiti Malaysia Pahang and Ministry of Education Malaysia for supporting the work financially under a project of FRGS (Fundamental Research Grant Scheme) no. RDU 130138 (Phase 2/2014).

\section{REFERENCES}

[1] Khalil HA, Hanida S, Kang C, Fuaad NN. Agro-hybrid composite: The effects on mechanical and physical properties of oil palm fiber (EFB)/glass hybrid reinforced polyester composites. Journal of Reinforced Plastics and Composites. 2007;26:203-18.

[2] Mohanty A, Misra M, Drzal L. Sustainable bio-composites from renewable resources: opportunities and challenges in the green materials world. Journal of Polymers and the Environment. 2002;10:19-26.

[3] Vilaseca F, Valadez-Gonzalez A, Herrera-Franco PJ, Pèlach MÀ, López JP, Mutjé P. Biocomposites from abaca strands and polypropylene. Part I: Evaluation of the tensile properties. Bioresource Technology. 2010;101:387-95.

[4] M. Khairul Zaimy AG, Zafiah A, Rus M, Ab Latif N, Nurulsaidatulsyida S. Mechanical and thermal properties of waste bio-polymer compound by hot compression molding technique. Journal of Mechanical Engineering and Sciences. 2013;5:582-91.

[5] Ibrahim MS, Sapuan SM, Faieza AA. Mechanical and thermal properties of composites from unsaturated polyester filled with oil palm ash. Journal of Mechanical Engineering and Sciences. 2012;2:133-47.

[6] Hardinnawirda K, SitiRabiatull Aisha I. Effect of Rice Husks as Filler in Polymer Matrix Composites. Journal of Mechanical Engineering and Sciences. 2012;2:181-6.

[7] Sumer Gaaz T, Sulong AB, Akhtar MN, Raza MR. Morphology and tensile properties of thermoplastic polyurethane-halloysite nanotube nanocomposites. International Journal of Automotive and Mechanical Engineering. 2015;12:284456.

[8] Mei GS, Yuvaraj AR, Kabeb SMb, Yusoff MM, Chigrinov VG, Hegde G. Biocompatible Polymer Embedded in Light-Sensitive Materials: Investigation of Structural Properties. International Journal of Automotive and Mechanical Engineering. 2014;10:2025-33.

[9] Mat Hassan NN, M. Rus AZ. Acoustic Performance of Green Polymer Foam from Renewable Resources after UV Exposure. International Journal of Automotive and Mechanical Engineering. 2014;9:1639-48.

[10] Azrin Hani AR, Shaari MF, Mohd Radzuan NS, Hashim MS, Ahmad R, Mariatti M. Analysis of Woven Natural Fiber Fabrics Prepared using Self-Designed Handloom. International Journal of Automotive and Mechanical Engineering. 2013;8:1197-206. 
[11] Taufik RS, Adibah M NF, Muhamad MR, Hasib H. Feasibility Study of Natural Fiber Composite Material for Engineering Application. Journal of Mechanical Engineering and Sciences. 2014;6:940-8.

[12] Umar AH, Zainudin ES, Sapuan SM. Effect of Accelerated Weathering on Tensile Properties of Kenaf Reinforced High-Density Polyethylene Composites. Journal of Mechanical Engineering and Sciences. 2012;2:198-205.

[13] Bachtiar D, Sapuan S, Hamdan MM. The effect of alkaline treatment on tensile properties of sugar palm fibre reinforced epoxy composites. Materials \& Design. 2008;29:1285-90.

[14] Shan CW, Ghazali MI, Idris MI. Improved vibration characteristics of flexible polyurethane foam via composite formation. International Journal of Automotive and Mechanical Engineering. 2013;7:1031-42.

[15] Then YY, Ibrahim NA, Zainuddin N, Ariffin H, Wan Yunus WMZ, Abd Rahman MF. Effect of Electron beam irradiation on the tensile properties of oil palm mesocarp fibre/poly(Butylene Succinate) biocomposites. International Journal of Automotive and Mechanical Engineering. 2014;10:2070-80.

[16] Ravi Sankar H, Srikant RR, Vamsi Krishna P, Bhujanga Rao V, Bangaru Babu P. Estimation of the dynamic properties of epoxy glass fabric composites with natural rubber particle inclusions. International Journal of Automotive and Mechanical Engineering. 2013;7:968-80.

[17] Ishak M, Leman Z, Sapuan S, Salleh M, Misri S. The effect of sea water treatment on the impact and flexural strength of sugar palm fibre reinforced epoxy composites. International Journal of Mechanical and Materials Engineering. 2009;4:316-20.

[18] Ishak M, Sapuan S, Leman Z, Rahman M, Anwar U, Siregar J. Sugar palm (Arenga pinnata): Its fibres, polymers and composites. Carbohydrate Polymers. 2013;91:699-710.

[19] Mogea JP. Revisi marga arenga (Palmae). Disertasi) Fakultas Pascasarjana UI Jakarta. 1991.

[20] Salit MS. Tropical natural fibres and their properties. tropical natural fibre. Composites: Springer; 2014. p. 15-38.

[21] Bogoeva-Gaceva G, Avella M, Malinconico M, Buzarovska A, Grozdanov A, Gentile G, et al. Natural fiber eco-composites. Polymer Composites. 2007;28:98107.

[22] John MJ, Anandjiwala RD. Recent developments in chemical modification and characterization of natural fiber-reinforced composites. Polymer Composites. 2008;29:187-207.

[23] Akil H, Omar M, Mazuki A, Safiee S, Ishak Z, Bakar AA. Kenaf fiber reinforced composites: a review. Materials \& Design. 2011;32:4107-21.

[24] Rong MZ, Zhang MQ, Liu Y, Yang GC, Zeng HM. The effect of fiber treatment on the mechanical properties of unidirectional sisal-reinforced epoxy composites. Composites Science and Technology. 2001;61:1437-47.

[25] Pandey JK, Ahn S, Lee CS, Mohanty AK, Misra M. Recent advances in the application of natural fiber based composites. Macromolecular Materials and Engineering. 2010;295:975-89.

[26] Gomes A, Matsuo T, Goda K, Ohgi J. Development and effect of alkali treatment on tensile properties of curaua fiber green composites. Composites Part A: Applied Science and Manufacturing. 2007;38:1811-20. 
[27] Bachtiar D, Sapuan S, Hamdan M. The influence of alkaline surface fibre treatment on the impact properties of sugar palm fibre-reinforced epoxy composites. Polymer-Plastics Technology and Engineering. 2009;48:379-83.

[28] El-Shekeil Y, Sapuan S, Khalina A, Zainudin E, Al-Shuja'a O. Effect of alkali treatment on mechanical and thermal properties of Kenaf fiber-reinforced thermoplastic polyurethane composite. Journal of Thermal Analysis and Calorimetry. 2012;109:1435-43.

[29] Taj S, Munawar MA, Khan S. Natural fiber-reinforced polymer composites. Proceedings-Pakistan Academy of Sciences. 2007;44:129.

[30] Sathishkumar T, Navaneethakrishnan P, Shankar S, Rajasekar R. Characterization of new cellulose sansevieria ehrenbergii fibers for polymer composites. Composite Interfaces. 2013;20:575-93.

[31] Alves C, Dias A, Diogo A, Ferrão P, Luz S, Silva A, et al. Eco-composite: the effects of the jute fiber treatments on the mechanical and environmental performance of the composite materials. Journal of Composite Materials. 2011;45:573-89.

[32] Graupner N. Application of lignin as natural adhesion promoter in cotton fibrereinforced poly (lactic acid)(PLA) composites. Journal of Materials Science. 2008;43:5222-9.

[33] Yussuf A, Massoumi I, Hassan A. Comparison of polylactic acid/kenaf and polylactic acid/rise husk composites: the influence of the natural fibers on the mechanical, thermal and biodegradability properties. Journal of Polymers and the Environment. 2010;18:422-9.

[34] Zhou Q, Cho D, Song BK, Kim H-J. Novel jute/polycardanol biocomposites: effect of fiber surface treatment on their properties. Composite Interfaces. 2009;16:781-95.

[35] Soykeabkaew N, Sian C, Gea S, Nishino T, Peijs T. All-cellulose nanocomposites by surface selective dissolution of bacterial cellulose. Cellulose. 2009;16:435-44.

[36] Liu D, Song J, Anderson DP, Chang PR, Hua Y. Bamboo fiber and its reinforced composites: structure and properties. Cellulose. 2012;19:1449-80.

[37] ASTM. D638, Standard test method for tensile properties of plastics. Dept. of Engineering Mechanics, Tongji U niversity, Shanghai 200092.

[38] Mohammed AA, Bachtiar D, Siregar JP, Rejab MRM. Development of sugar palm fibre reinforced thermoplastic polyurethane composites: optimization of processing and fibre size. Submitted to the e-polymer 2015.

[39] Mohammed AA, Bachtiar D, and Rejab MRM. The effect of fibre loading on the mechanical properties of sugar palm fibre reinforced base thermoplastic polyurethane composites. Submitted to the materials Science and Engineering: A. 2015.

[40] El-Shekeil Y, Sapuan S, Zainudin E, Khalina A. Optimizing processing parameters and fiber size for kenaf fiber reinforced thermoplastic polyurethane composite. Key Engineering Materials: Trans Tech Publ; 2011. p. 297-302.

[41] Mohanty A, Misra M, Drzal L. Surface modifications of natural fibers and performance of the resulting biocomposites: an overview. Composite Interfaces. 2001;8:313-43.

[42] Xue L, Lope, G.T., \& Satyanarayan. Chemical treatment of natural fibre for use in natural fibre-reinforced composites: A review. Polymer Environment,. 2007; $15: 25-33$. 
Effect of sodium hydroxide on the tensile properties of sugar palm fibre reinforced thermoplastic polyurethane composites

[43] Joseph K, Thomas S, Pavithran C. Effect of chemical treatment on the tensile properties of short sisal fibre-reinforced polyethylene composites. Polymer. 1996;37:5139-49.

[44] Zheng Y, Liu Y, Wang A. Kapok fiber oriented polyaniline for removal of sulfonated dyes. Industrial \& Engineering Chemistry Research. 2012;51:1007987. 